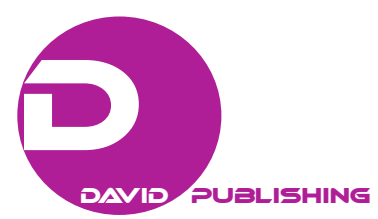

\title{
From Knowledge to Wisdom: The Case of a Micro-financing Network
}

\author{
Nouha Taifi \\ University Mohammed V, Rabat, Morocco \\ Khaddouj Gharbi \\ Pedagogy Regional Center and Réseau MicroFinance Solidaire, Rabat, Morocco
}

\begin{abstract}
As one of the most important and strategic actors of sustainable development, the micro-financing (MF) organizations are continuously adopting new strategic methods of collaboration for the success of their micro-financing missions. The paper presents the case of a newly established network of MF organizations created for the strategic objective of not only collaboration but for optimizing inter-organizational knowledge sharing systems for the micro-financing services. The purpose of the paper is to show the method used for the creation of this network, the mechanisms for its management, and the dynamisms and success factors leading to its continuous development. The findings are derived from an interview with one of its most strategic founders, and material is provided by the network, and a questionnaire is administered to the members of the network. The results imply theoretical implications to innovation management and organizational development and change since the source of the creation of this network is innovative, and for the competencies of the founders and their awareness of the importance of change lead to the creation of this network. And the results also lead to managerial implications in the micro-financing sector through the provision of a unique excellent command example to follow.
\end{abstract}

Keywords: micro-financing, inter-organizational collaboration, networks, strategic communities

\section{Introduction}

The small and medium organizations are often the result of investment based on micro-financing support. The latter is one of the most important contributors to poverty reduction and economic development. It is also a strategic actor in social entrepreneurship and social innovation in general. According to Armendáriz and Morduch (2005), the positive impact and benefits of micro-financing are not only shown through storytelling and anecdotes but also through statistical measurement in a global scale and provide interesting cases with longitudinal data and methodological analysis. Recently, the micro-financing sector, usually adopted in

Acknowledgements: The research is one of the first results of a larger scientific research project concerning knowledge, technology, and innovation management in the micro-financing sector. Also, the authors would like to thank the respondents to the questionnaire, the interviewee, and the network for the data and material provided for the research. Technology and Organizational Management for the micro-financing sector, funded by the ATTADAMOUNE Micro-finance Association, Fez, Morocco, ref. 2012 /R\&D/ N. 3.

Nouha Taifi, Ph.D., assistant professor, Industrial Engineering Department, Mohammadia School of Engineering, University Mohammed V, Rabat, Morocco.

Khaddouj Gharbi, Ph.D., professor, Pedagogy Regional Center and Réseau MicroFinance Solidaire, Rabat, Morocco.

Correspondence concerning this article should be addressed to Nouha Taifi, Industrial Engineering Department, Mohammadia School of Engineering, University Mohammed V, Avenue Ibn Sina, 10090, Rabat, Morocco. 
under-developed and developing countries, has been also given great consideration in period of economic crisis in developed countries. One of the key players for this is Grameen Bank for instance in the United States and the Free Loan Association in Israel (IFLA). The micro-financing sector is one of the most expert sectors in business management under less favorable conditions. For this, the interest of management scholars and business practitioners is growing toward the investigation on its strategies of development, collaboration, and management. According to Antohi (2009), the micro-financing sector is a social capital for innovation and a strategic social source of local development (Lebossé \& Wallace, 1998). Also, it consists of various technological systems for its strategic management (Taifi \& Gharbi, 2013).

The micro-financing institutions that are widely spread in under-developed and developing countries since decades, have competences and expertise in this domain as a result of long-term activities and are further developing managerial and strategic competencies for to be aligned and overcome the challenges of the $21 \mathrm{st}$ century paradigms that is urging firms to adopt information and communication technologies and strategic organizational structures of collaboration. In order to continuously develop this social sector, its organizations need to be expert and have competences about the social sector and thus know its characteristics (Sapovadia, 2006). Social entrepreneurship is characterized by the objectives of creating social value, the use of innovation, and overcoming challenges in resources scarcity (Peredo \& McLean, 2005). Social enterprises are considered as a mix of profit, private, and non-profit organizations (Dees, 1998). Besides, the research study of Short, Moss, and Lumpkin (2009) states that multivariate methods need to be inserted in research about social entrepreneurship and that various types of theories need to be used as contingency theory and innovation diffusion theory in order to make strategic research on social entrepreneurship.

Besides, concerning innovation management, Tidd (2012) develops on the move of the knowledge management towards strategic competences stating that there are capacities, mechanisms, and routines for innovation; for instance, the research of Brion, Mothe, and Sabatier (2012) analyze, based on competences management, the method in which innovation is enhanced according to the organizational contexts. Following these researches, the question here is to further investigate on the strategies and methodologies used in the micro-financing sector so as to pace with the increasing paradigms of the 21 st century because the micro-financing institutions are also organizations based on business and management principles and do face moments of issues and crisis in which they have to brainstorm, innovate, and change to continue their development. It is mentioned that there are already several research studying micro-financing sectors from an epistemological and ontological level (Table 1). As an example, the researches of Bruton, Khavul, and Chavez (2011) and Mothe and Sabatier (2011) presented a framework, from an international business perspective, for the analysis of the micro-lending economic performance in order to face and to overcome the threats of micro-lending on international business. Also, the work of Bruton et al. (2011) makes a study on the micro-lending beneficients stating that there are causes and consequences of business performance or failure and this depends on the MC borrowers' behavior. And the research of Aderibigbe (2001) states it is necessary to take into consideration the international practices in order to continue building an optimal micro-financing sector. There is also the research of Bin Mislan, Hadisumarto, and Ismail (2010), on islamic micro-financing presenting a method to develop the effectiveness of micro-financing and thus they stated that the precedent processes of development are efficient, however, an integrated program is to be devised to further facilitate the development of the MF sector and this needs to be based on spiritual values. 
Table 1

Some Relevant Literature on MFIs, SMEs, Their Performances and Impacts

\begin{tabular}{|l|l|}
\hline Micro-financing topics & Relevant literature \\
\hline Micro-financing institutions impact on SMEs & $\begin{array}{l}\text { Armendáriz and Morduch (2005); Benjelloun (2006); Duvendack et al. } \\
\text { (2011); Zapalska, Brozik, and Rudd (2007); Galak, Small, and Stephen (2011) }\end{array}$ \\
\hline $\begin{array}{l}\text { Small and medium institutions impact on the } \\
\text { economic performance }\end{array}$ & Ayanwale and Alimi (2004); Nader (2008) \\
\hline SMEs performance & Bruton et al. (2011) \\
\hline Micro-financing institutions performance & $\begin{array}{l}\text { Antohi (2009); Lebossé and Wallace (1998); Bruton, Mothe, and Sabatier } \\
\text { (2011); Aderibigbe (2001); Bin Mislan et al. (2010); Hartungi (2007) }\end{array}$ \\
\hline Micro-financing institutions impact on economy & Armendáriz and Morduch (2005); Khandelwal (2007) \\
\hline
\end{tabular}

Besides, the research study of Short, Moss, and Lumpkin (2009) states that multivariate methods need to be inserted in research about social entrepreneurship and that various types of theories need to be used as contingency theory and innovation diffusion theory in order to make strategic research on social entrepreneurship. Therefore, following these various researches on micro-financing, the objective of this paper is to present a case study showing the development of the micro-financing sector in which there is the creation of new initiatives. The research paper is mostly at the organizational and managerial levels of investigation. The case study is related to the creation and development of a network of the most expert micro-financing institutions and its management in a developing country. The paper is divided as follows: The next section presents the literature related to the importance of micro-financing in the economic and social environment. The third section presents the research framework in which the idea behind the investigation on the case study is explained and the research methodology as well. The fourth section presents the findings derived from the analysis of this network and its managerial methodology. And finally, there is a discussion and the implications for theory and practice.

\section{Background}

\section{Micro-financing: A Social and Economic Development Engine}

The micro-financing institutions in the world are one of the most important actors in economical and societal development. They participate actively in overcoming poverty of the poorest and at the same time continuously support the organizations that are created. They have various success factors as fast adaptation to the environment, efficient MF loans characteristics, efficient and trained staff, and optimal financial processes and systems for the on-going operations of the Micro-financing (Hartungi, 2007). The MF services to their beneficents range from small and medium loans to integration-support in the society (Table 2); as the benefients use these loans as they overcome poverty and enter into the human and personal development society (Benjelloun, 2006); the research of Duvendack, Palmer-Jones, Copestake, Hooper, Loke, and Rao (2011) evaluates the impact of micro-financing on the borrowers and the economy in general stating that there is a contradictory research on the positive and negative impact of micro-financing, then, this research through a systematic review confirms that these types of evaluations can mislead the micro-finance sector toward more efficient and innovative methodologies for its proper development. For this, it is also necessary to take into consideration that the small and medium organizations in the micro-financing sector are one of the key players in the business environment and their economic performance when high contribute to the global economic development; Bruton et al. (2011) made a study on the micro-lending beneficients stating that there are causes and consequences of business performance or failure and this depends on the MC borrowers' behavior. 
Table 2

The Types of Micro-financing Services

\begin{tabular}{|l|l|}
\hline MF services & Description \\
\hline MF loans & $\begin{array}{l}\text { - Loans requested for the launch of a micro, small, or medium enterprise or project } \\
\text { and their amounts do not exceed the regular bank loan. }\end{array}$ \\
\hline Societal integration & $\begin{array}{l}\text { - Support to the micro-loans entrepreneurs for the awareness acquisition about the } \\
\text { impact of their entrepreneurial initiative as an action to their integration into society. }\end{array}$ \\
\hline
\end{tabular}

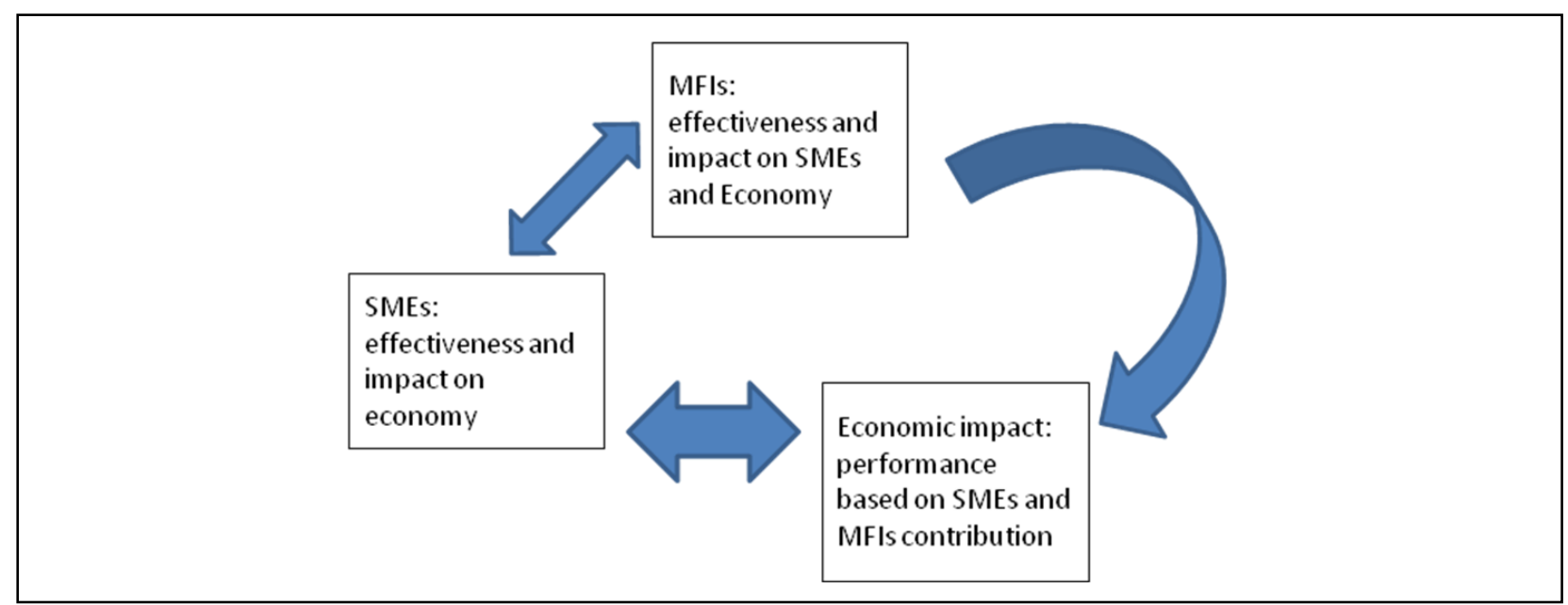

Figure 1. MFIs, SMEs, and economic impact.

\section{Micro-financing: Organizational and Operational Competencies and Capacities}

As an engine to the social and economic development, the micro-financing institutions rely on their roles as MF service providers through their internal and external ongoing-operations for an optimal MF services provision. For instance, in the research of Zapalska, Brozik, and Rudd (2007), micro-financing institutions as Grameen Bank provide entrepreneurial capacities for micro-credit borrowers, and have the objective of financial innovations for the development of lower costs of transactions and of credits. They also base their operations on clear and updated regulations and most important qualified human resources; for instance, as a regulation, the research of Galak, Small, and Stephen (2011) states that micro-financing institutions focus on MC provision to individuals or groups that have social proximity. Also, the social entrepreneurship of the micro-financing institutions and the small and medium enterprises themselves lead to effectiveness and performance in the economy (Figure 1). For instance, the important research of Murisa and Chikweche (2013) on enterpreneurship and micro-finance states that there are challenges to entrepreneurship that has solutions and that MF has great potential to impact the population. Also, the research of Afrane (2002) makes an impact assessment of MF and finds out that MF contributes significantly to business performance and social integration of the population. And, concerning gender MF perspectives on research, there is for instance the research of Nader (2008) stating that MF impacts the well-being of women and their entire families and thus improves health, education of children, and income. The research of Ayanwale and Alimi (2004) on gender acquisition of loans from NGOs states that mostly women get higher loans than men to encourage more their enterpreneurial spirit and that incomes are higher for men than women but that in average the income is better than before loan provision.

Also, thus it is clear that the MF engine for development has internal and external actors playing specific roles and taking actions based on specific operational processes and information systems architectures and 
partnerships. The research of Khandelwal (2007) on the importance of micro-financing insitutions, presents their unique characteristics in MF services and their economic benefits compared to regular banking organizations. Thus, these MF engines have thus the organizational and operations competencies and capacities leading to the success of their internal environment and their MF services (Figure 2). The micro-financing institutions focus on MF services provision to established types of enterpreneurial initiatives which make this sector an attractive environment for investors.

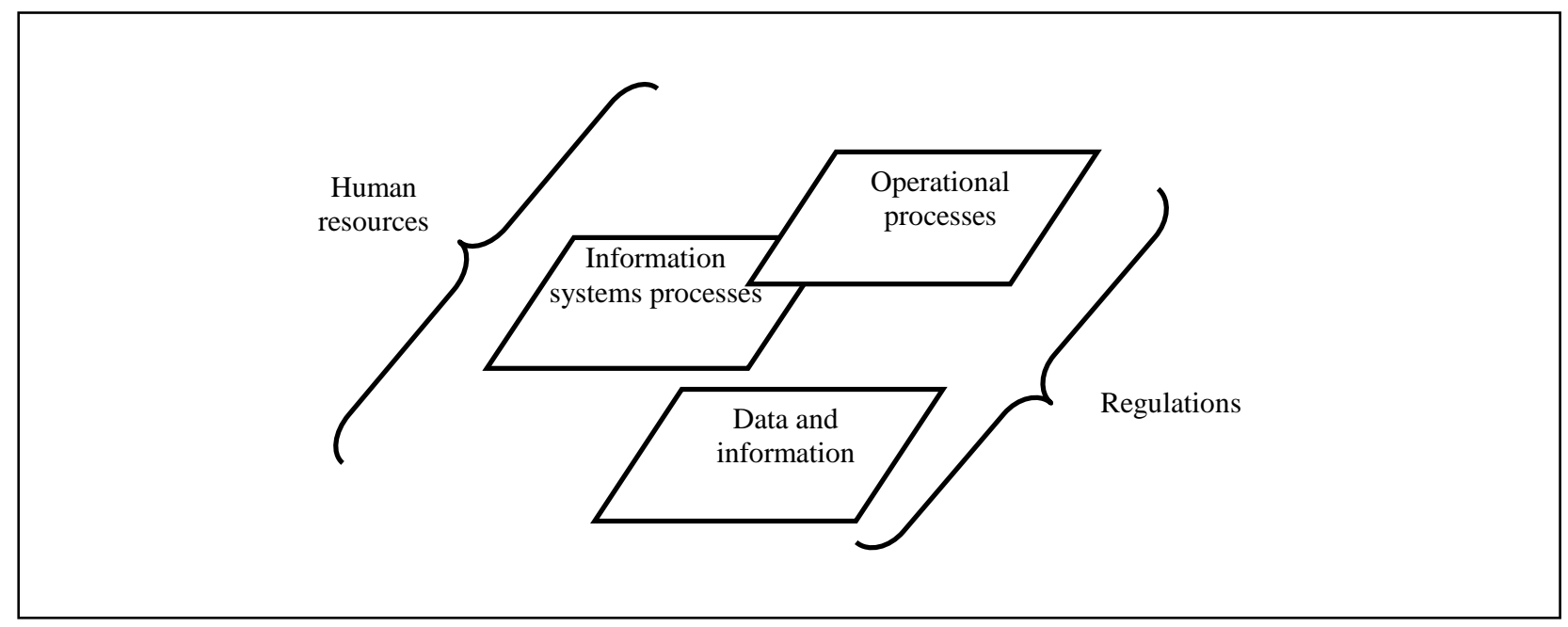

Figure 2. The MF important success factors.

\section{Research Framework}

\section{Knowledge and Network-Based Organizations}

As entities of collaboration, the organizations in all types of environments have the adequate data, information, and knowledge according to their functions, operations, and business purposes in the environment. Thus, they base their activities on not only knowledge residing within the boundaries of their organizations but also on knowledge acquired or shared in an inter-organizational manner through their network of collaborators, partners, or co-opetitors. The strategic alliances are important for business performance and innovation since they permit to the firms to react swiftly to market needs (Shan, Walker, \& Kogut, 1994; Baum, Calabrese, \& Silverman, 2000) and to manage the time element that is critical to economic performance and competitive advantage (Yoshino \& Rangan, 1995). And, the strategic networks are composed of inter-organizational ties that are based on social, professional, and exchange relationships (Gulati, 1998), and these can be virtual environments without physical borders of separation and based on technological infrastructures (Lipnack \& Stamps, 1997). The context in which these knowledge-based (KB) and network-based (NB) organizations reside differs from one environment to the other, however, according to Nonaka and Takeuchi (1995) in all cases, through inter-organizational collaboration there is knowledge combination and socialization which shows the objective of network creation (Figure 3). For instance, in the context of micro-financing the managerial practices differences among finance and MF institutions strengthen collaboration among them (Roubos, 2008). Besides, in an economic research in the context of micro-financing institutions and MC-borrowers allocation, Taifi (2004) mentioned there is no better method to build capacities in MF institutions than the structural exchange of experience among the practitioners' organizations. 


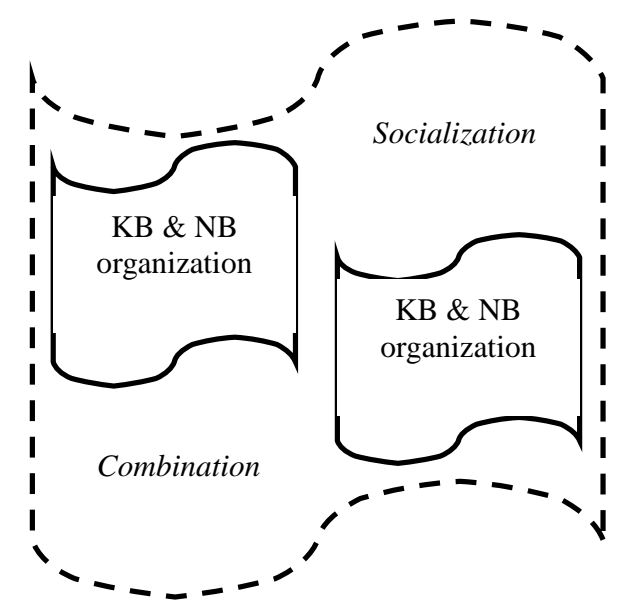

Figure 3. Knowledge sharing within the network.

\section{Research Statement}

In the context of micro-financing institutions, there are no operational activities without collaboration among various other actors in the environment. In fact, if taken into consideration, the example of funding institutions, supporting MF organizations, shows there is inter-organizational collaboration, thus network-based processes (Table 3); for instance, Morton (1997) presented the important role of USAID fundings in providing support for the quality, performance of the credit unions in Africa. Also, Alade, Sharma, and Sharma (2003) mentioned that MF institutions mostly rely on funding institutions and public sources at subsidized rate; it is only in the long-term operations that private funds are reached. Also, for instance, the inter-organizational collaboration of MF institutions with management control or auditing organizations shows again a network manner and knowledge sharing process of collaboration (Table 2). Also, at the social enterpreneurship level of analysis, these formations of partnerships among different actors can be considered as the results of the social entrepreneurship actions and process of the different actors in the micro-financing sector and empowering further social entrepreneurship actions (Figure 4).

Thus, in the micro-financing sector, there are network- and knowledge-based organizations, formed by social entrepreneurs and leading to social entrepreneurship, and various types of networks and knowledge according to the context and objectives of collaboration, and the continuous investigation on their types is more than a strategic topic to further research on. For instance, through a social network analysis, Chen and Krauskopf's (2011) research study present a merger between two non-profit organizations in the micro-financing sector and demonstrate that the executives need to not only integrate the formal structures but also develop the informal inter-relationships among the human capital of the organizations and to provide them with necessary support for the development of their competences and work activities.

Table 3

Types of KB and NB Organizations

\begin{tabular}{|l|l|l|}
\hline Type of KB & Role & Network focus \\
\hline Funding institutions & Financial support to MF & Sufficient financial resources for MF loans \\
\hline Monitoring institutions & Management support to MF & Quality optimization of the operations \\
\hline
\end{tabular}




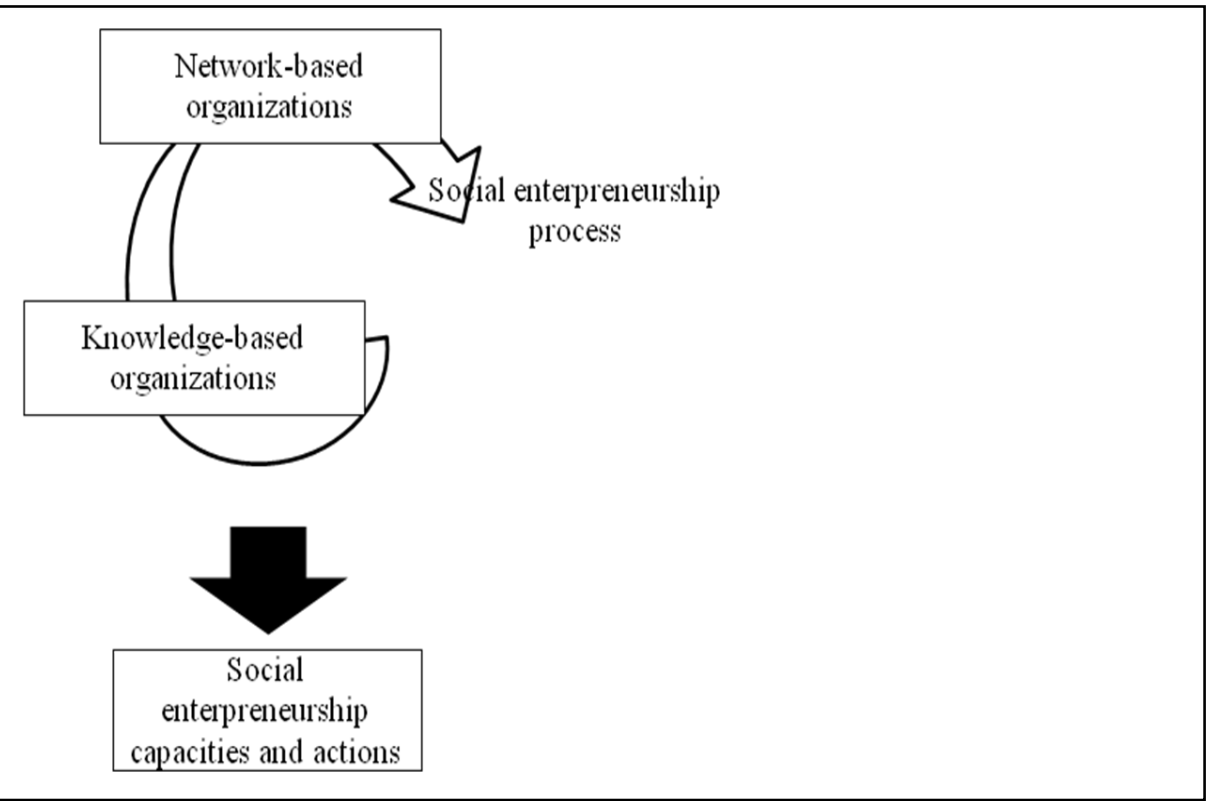

Figure 4. Pillars of success in social enterpreneurship engineering in the MF sector.

The actual research in this paper would like to analyze and research on a new and larger type of network focus devised by MF institutions. And in fact, the micro-financing sector is continuously in development; the paper presents a new typology of collaboration adopted in this sector and investigates on its strategic mechanisms and dynamisms. This network formation is also a new type of social entrepreneurship that is expected to bring new social values to the micro-financing sector and resolve various types of issues and challenges in this social sector. Thus, focusing on the organizational, managerial, and strategic levels of investigation, this research framed the following research questions:

- What type of network-based organizations is this? Through answering this question, the research paper aims at the identification of the types of structural ties among the members of the network and their functions and roles;

- What are the mechanisms used for its management? This question aims at the investigation on the operations and activities of the network leading to its functioning in an optimal manner;

- What are the strategic dynamisms leading to its success? This question aims at the analysis of the most strategic aspects leading to the success and sustainable development of the network.

\section{Research Methodology}

In this research paper, in order to answer the research questions and follow the background and research framework, the research is conducted on this new type of inter-organizational collaboration in the micro-financing sector. The case study research method is an empirical research investigating on a phenomenon within its real-life context (Yin, 2009). The research framework is used to investigate on the network and knowledge focus of this collaboration, its mechanisms, and strategic dynamisms. Data were collected through the following data collection method:

- Brief interview with one of its most strategic founders concerning the network structure and ties, and its most strategic aspects. The responses provided further data about the network dynamisms and mechanisms as for example the initial means used for the network creation and the specific objectives of the network; 
- Regular meetings with the people involved in the creation and management of the network. These meetings have been held on a monthly basis since October 2010. These meetings provided data and information about the on-going progress of the creation and development of the network-for instance, the identification of key obstacles to the development or the integration of new collaborations and partnerships for the development.

- Data and material provided by its founders and consisting in its mission, vision, and regulations. These data and materials allow the identification of the objectives, the members, and regulations of the network in more specific details.

- A questionnaire (Table 4) dedicated to the members of the network that are micro-financing institutions and responsible of the on-going operations and sustainable development of the network structure. In general, the questionnaire investigates on the profile, means for the creation of network, and types of resources of the network.

Table 4

The Questionnaire Sections

\begin{tabular}{|l|l|}
\hline Questionnaire sections & Description \\
\hline Respondent profile & $\begin{array}{l}\text { This section regards the identification of the expertise of the respondent in the field of } \\
\text { micro-finance and its point of view on the objectives of the new inter-organizational } \\
\text { collaboration. }\end{array}$ \\
\hline Creation and development strategy & $\begin{array}{l}\text { This section regards the analysis of the origins of the idea of creation of this new entity and } \\
\text { the methodology used for its development. }\end{array}$ \\
\hline Types of resources & $\begin{array}{l}\text { This section regards the identification of the different resources used as a support to the } \\
\text { creation and on-going operations of the inter-organizational collaboration. }\end{array}$ \\
\hline Continuous improvement strategy & $\begin{array}{l}\text { This section regards the investigation on the strategy adopted by the founders for to pace } \\
\text { with needed changes in this inter-organizational collaboration for optimal collaboration. }\end{array}$ \\
\hline
\end{tabular}

The objective of the questionnaire was to investigate on the profile of the respondent, the strategy of creation and development, the types of resources used for the creation and management, and the strategy of continuous improvement and re-engineering. Table 3 summarizes the questionnaire. Following is the content of the questionnaire:

- The first section of the questionnaire investigates for example on the profile of the respondent that is a member of one of the micro-financing institutions; the questions analyze the level of experience and expertise of the member in the MF sector - this assumes the quantity of knowledge and experience about the MF sector is important for the inception of the network.

- The second section investigates on the origins of creation of the network and on the methodology used for this; so for instance, some questions focus on the identification of the obstacles to the creation and development of the network and on the inter-organizational collaborations of the network for its inception and development. These questions lead to the identification of the type of network created whether decentralized or centralized.

- The third section investigates on the resources of the network ranging from technological to organizational for the development and operations of the network; so for instance, the questions regard the various means of communication among the members of the network and their perceived usefulness. These questions regard the mechanisms of creation and development of the network.

- The fourth section of the questionnaire investigates on the strategy put in place for the continuous development of the network as whether there are plans for the further development of the resources, managerial, and strategic activities. These questions lead to the identification of the strategic dynamisms of the creation and development of the network. 
So, in addition to the other data collection methods, the questionnaire was expected to bring relevant data and information for the achievement of the research objectives. The questions were open-ended questions and semi-closed-ended questions with a response with a yes or no and comments on the response. The researchers started sending the questionnaire by email to the network's members in June 2011 and the collection of the questionnaire proceeded until December 2011. The questionnaire was sent to all eight members of the network and six responses were received, which represents $75 \%$ of the population of the network and a valid and reliable percentage for the presentation of the results.

\section{Results}

\section{The Network Origins and Its Members}

The creation of this network emerged from the willingness of seven micro-financing institutions to further develop their collaboration and the micro-financing sectors. The creation of this network is also supported financially by one of the members of the network that is a banking institution and that has the most strategic players in the grand sister of this network that is a national federation of micro-financing institutions; the members of the network are members of this federation as well. The network headquarter is located in one of the most important MF active regions in this country and has been created in mid-year of 2010.

As stated by a respondent, "the MF financing institutions have each different objectives, resources and capacities", thus, the main objectives of the network are to integrate the information systems among its members and to share strategic data and information about micro-financing so as to accelerate the development of the micro-credit small and medium enterprises and to optimize the management of the micro-financing institutions. As stated by an MF institution, "the objective of the network is to coordinate the activities, to share good practices, and to sustain development", also, another statement is "one of the objective of the network is to bring support to MF institutions during their interactions with the governmental authorities" or "the objective of the network is to strengthen the synergies among the MF institutions, to support them in financial funds raising, and to provide mere assistance to MF institutions in crisis phases".

In more details, the objectives of the network are as follows:

- Standardization of the MF institutions management; that is, the accounting, reporting, financing, and other administrative activities;

- Optimization of each of the seven MF institutions operations through the increase of the quality of the functions and processes and the standardization of the entire management;

- Development of the relationships among the MF institutions through the creation of strong ties among them so as to continuously share information, knowledge, and competencies, and be motivated to do that; as stated by one of the founders, "the willingness and the participation of the members in the network activities will ensure the development of the network";

- Continuous development of the integrated systems among the members of the network through information and knowledge acquired through the network collaborations;

- Control and monitoring among the members according to their geographical proximity;

- Homogeneous governance and transparency among the members;

- Provision of the right support to the small and medium enterprises as accounting, regulations, and reporting.

The founders of the network have key roles in these seven micro-financing institutions and most of them also have other primary functions in other sectors. According to Ahuja (2000), the network partners have 
different skills and competences and each network member benefits from the network expertise without extra costs. In the MF network, only $17 \%$ of the respondents operate in the micro-financing sector. Their activities in other sectors are academicians, financial executives, consultants, and bank managers and these functions are in the public and private sectors (Table 5) and most of them have long-term active participation in the micro-financing sector; only 17\% have less than three years, 33\% have less than eight years and the others have more than 12 years of expertise in this MF sector (Figure 5).

Table 5

Respondents' Secondary Profile in Addition to the MF Activities

\begin{tabular}{|l|l|}
\hline $\begin{array}{l}\text { Respondents' secondary profile } \\
\text { (private and public sector) }\end{array}$ & Description \\
\hline Academicians & $\begin{array}{l}\text { Higher education and scientific research and development at higher } \\
\text { education institutions, universities, and research centers }\end{array}$ \\
\hline Financial executives & Financial analysis and forecasting, accounting, auditing... \\
\hline Consultants & Analysis and optimization of managerial practices of the organizations \\
\hline Bank managers & Management of bank accounts, financial analysis, and services \\
\hline
\end{tabular}

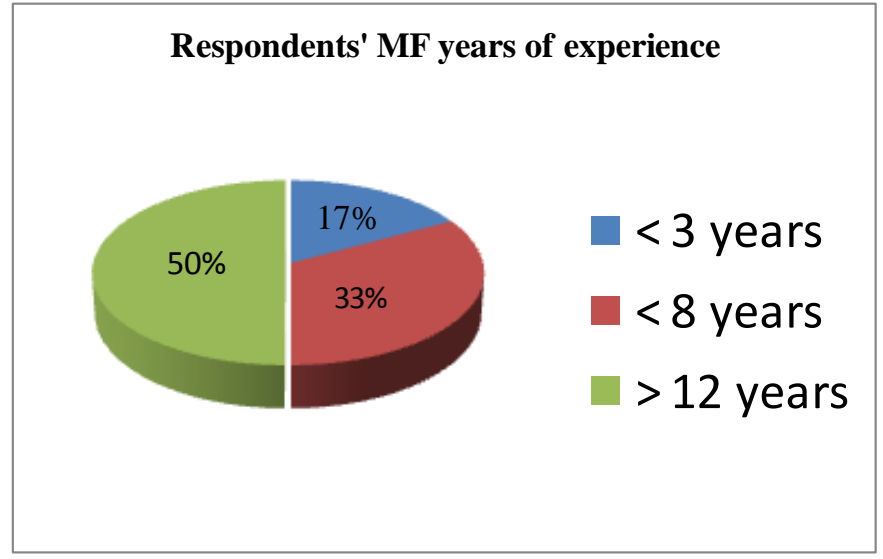

Figure 5. Different years of experience of the respondents in the MF.

The founders of the network have specific roles and functions in their micro-financing institutions and in the network; in the MF institutions, they are the presidents and within the network, they are the members board, however, only $17 \%$ of the respondents consider there is ambiguity in the role played by each MF institution in the network; that is, there is not a clear understanding about the difference between being a member of the network and being a member of a MF institution (Figure 6). The founders of the network and president of their MF institution have the power to delegate functions and missions to members of their MF institutions for the network services or assume them by themselves, however, 33\% of the respondents believe there is a lack of consultancy and cooperation in the entire network or $16 \%$ of the respondents believe there is a time delay in the achievement of the network creation objectives (Figure 6). According to Dyer and Singh (1998), managing the network involves using appropriate governance mechanisms, developing inter-firm knowledge, sharing routines, making appropriate relationship-specific investments, and initiating necessary changes to the partnership as it evolves while also managing partner expectations. In this MF network, there are various types of functions and roles in which the board members and their delegates take action; as stated by an MF institution, "each MF institution has different levels of engagement in the network". For instance, there is the role of executive 
director, general secretary, network performance evaluator, external environment-partners-manager, information sharing evaluator, and optimizer.

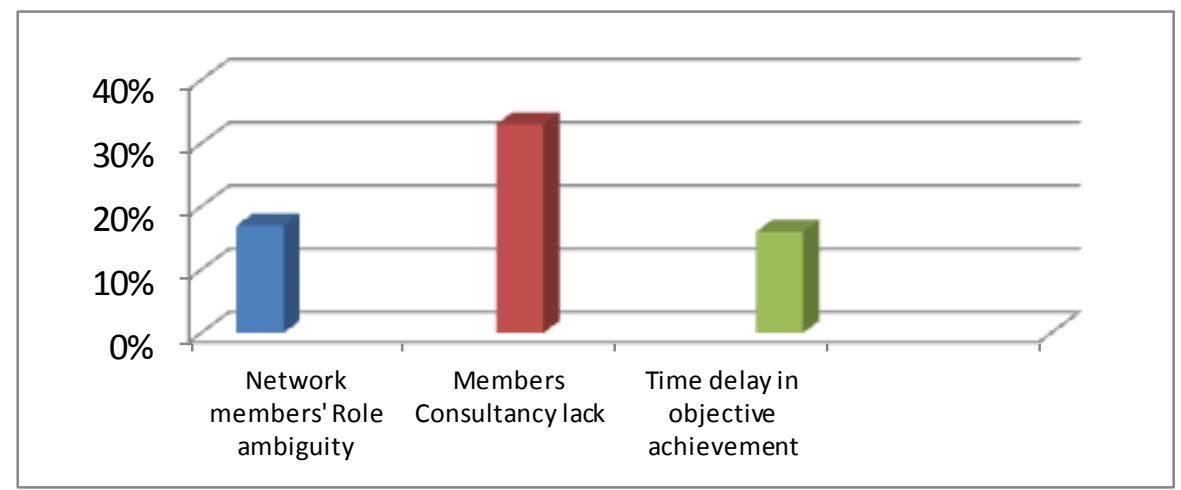

Figure 6. Representation of minor issues of the network.

\section{Strategic Processes and Practices}

The network is continuously willing to increase the number of its external partners when needed; $33 \%$ of the respondents would like to have more partners experts and consultants in micro-financing; $17 \%$ believe that as partners, non-governmental organizations would be suitable, and $17 \%$ believe partners will be essential for the development of homogeneous inter-organizational processes and systems. Also, 17\% of the respondents state that the external partners will be useful for the network members who are sometimes unavailable so to substitute them and that this can be through official hiring and recruitment.

Finally, 33\% of the respondents state that external partners' functions and roles are essential in the organizational, procedural, regulations, management control, projects management, information systems, and communication aspects development (Figure 7).

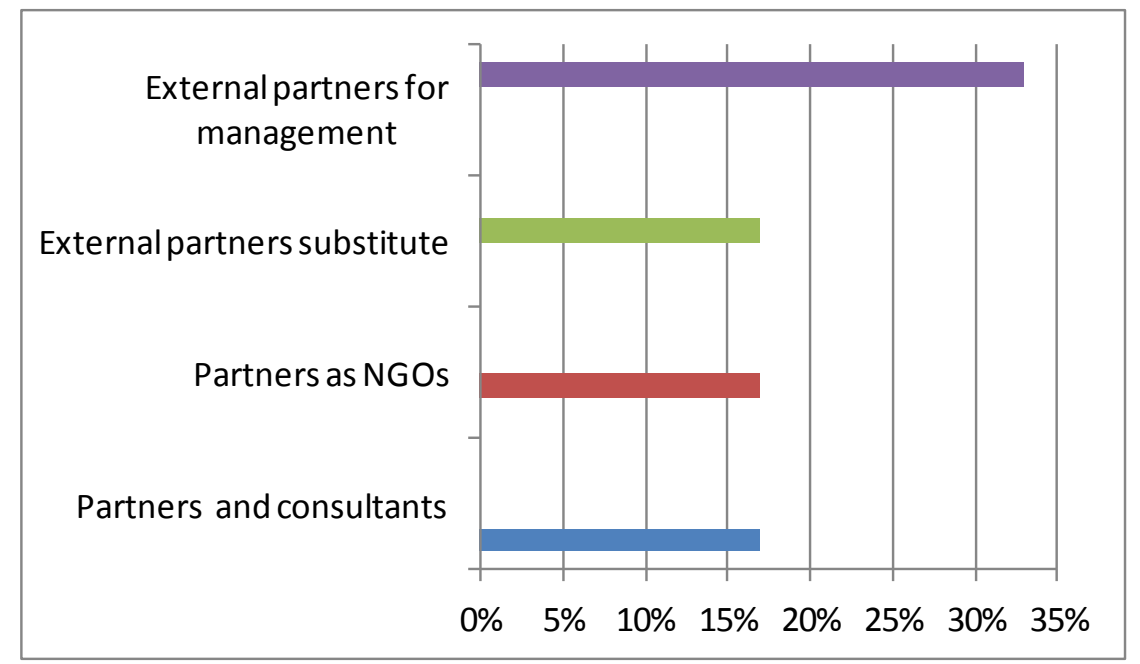

Figure 7. Different roles of external partners to the network.

The information systems of the network are based on various types of communication tools and systems; they are face to face and IT-based interactions (Table 6). The network members organize meetings and seminars and/or share information and knowledge via emails. They also benefit from professional trainings 
organized when there are new services or products in the micro-financing sector. Besides, an IT-based management information system named SIG is in the phase of development and application within the network so as to accelerate and optimize information and knowledge sharing. The network members are subject to professional training for the understanding and optimal use of the information management system and two network's members already started using it in January and April 2012. Information and communication technologies dedicated to the network organizations are majorly integrated and have specific purposes as to use potential new ways of organizing work activities (Symon, 2010; Taifi \& Gharbi, 2013).

Table 6

The Different Means of Communication and Management of the Network

\begin{tabular}{|l|l|}
\hline Means of communication and management & \\
\hline Face to face & Meetings, seminars, and professional training \\
\hline IT-based & Emails, IT-information system \\
\hline
\end{tabular}

According to Orlikowski and Robey (1991), information technologies contribute to the structuring of the organization (Barley, 1991), but it is also the product of human actions in different contexts and it shapes and redesigns these contexts. Through the MF network MIS, its members are able to access, through login, their account and use the data management applications on the system to develop accounting, financing, and reporting documents that are standardized and unified among all members of the network. Also, in the context of the social services sector, Zhang and Gutierrez (2007) stated that in IT adoption, the users of specific systems also provide major contributions to their organizations and customers. Also, this system utility is to interact with the members of the network and with the external partners and fund raisers. The objective of this management information system is also to reduce costs of IT-based information systems management and maintenance within each single micro-financing institution since it allows for an integration of the systems among them (Taifi \& Gharbi, 2013); the network members as non-profit organizations have specific financial funds and budgets and these information systems contribute to the cost-savings within their organizations.

\section{Continuous Innovation Network}

The network members have also suggested various strategies to continuously improve the information sharing and communication and the development of the entire network (Figure 8). Some of the respondents state that "through the development of the network and its expansion, it could become an organization with economical interest in the case of individual micro-financing institutions not reaching self-sustainability". Other statements concerning becoming a profit organization is "...depending on the nature and specifications of its micro-financing activities" or "...through the integration of the micro-financing institutions management" or "... in the short-term, in the first phases of organizational structure and management set-up". Indeed, if considered as social enterprise, the micro-financing institutions, although considered before as non-profit organizations (Chell, 2007), are now more as a merger of profit, public, and private-based organizations.

Besides, as suggestions, the network members perceive the devise of a monthly magazine, report, or newspaper as highly useful so as to add another information tool to the information sharing systems of the network and to keep all members updated about new initiatives, products, and services in the micro-financing network and sector. According to Tiwana and McLean (2005), the integration of the expertise and creativity skills of users in the IT-project development phase leads to new products and services innovation. The members of the network also believe it is necessary to have a network website dedicated to the diffusion of the 
existence of the network on the web, its objectives, and functions and to use it as a support to attract more partners and fundraisers and as a means for further inter-organizational communication and information sharing among the network members.

Finally, concerning higher strategic decisions-making, 50\% of the respondents state the network has capacities and competences to overcome difficult periods of changes in the network as for instance in the case in which individual MF institutions face a crisis phase. Also, as stated by a respondent, "as long as each individual MF institution keeps its own identity, management, its own products and has an independent management in the face of crisis of the network, the most important is to recover its database" so as to keep information, knowledge, and expertise to remedy to the issues faced. The databases will support the network members in strategic analysis of the most critical situations. Moreover, the creation of this network by itself and the objectives of its inception are a solution to extreme cases to end up with zero-trauma crisis and changes to the MF institutions. According to Franciscus, Koppenjan, and Klijn (2004), uncertainties management in the environment can be through the network approach calling for the development of mutual adjustments and cooperation, and joint decision making for the improvement of problem-solving.

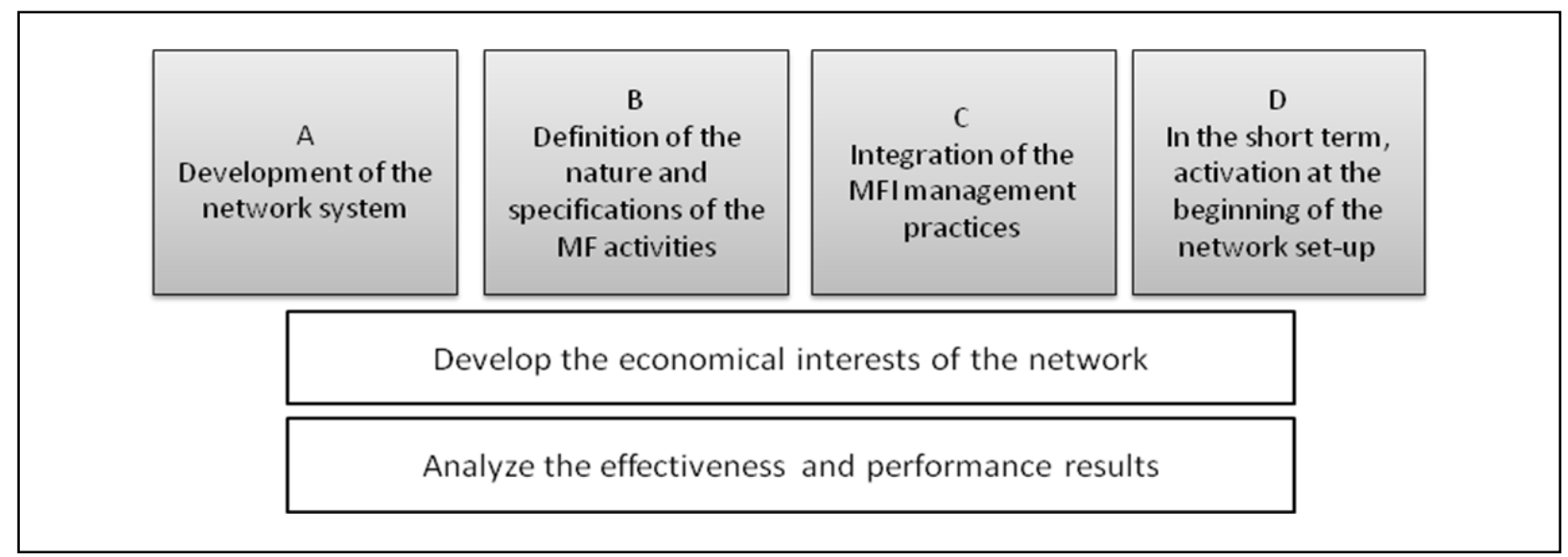

Figure 8. Activation process of the social-economical entrepreneurship of the network.

\section{Discussion}

The purpose of the study is to further investigate on the network-based and knowledge-based organizations in the micro-financing sector and the social entrepreneurship undergone to activate social and economic performance because the engineering of social enterpreneurship in the micro-financing sector requires new models and approaches. According to Kanter (1999), the social sector is moving toward being a source of innovation and new managerial approaches adoption. Also, Sagaw and Segal (1999) stated that value creation in the social sector arises through business-social sector partnerships. The research focused on the analysis of the mechanisms and dynamisms of a new type of inter-organizational collaboration and its network focus. The results show that this case study has various important objectives, strategic processes, and practices and that it is a continuous innovation network. In particular, the development of social enterpreneurship capacities and actions should be based on knowledge, experience, and methods which make social enterpreneurship a process where its actors as the MFIs and their networks are experts based on sustainable processes of entrepreneurship (Figure 9). 


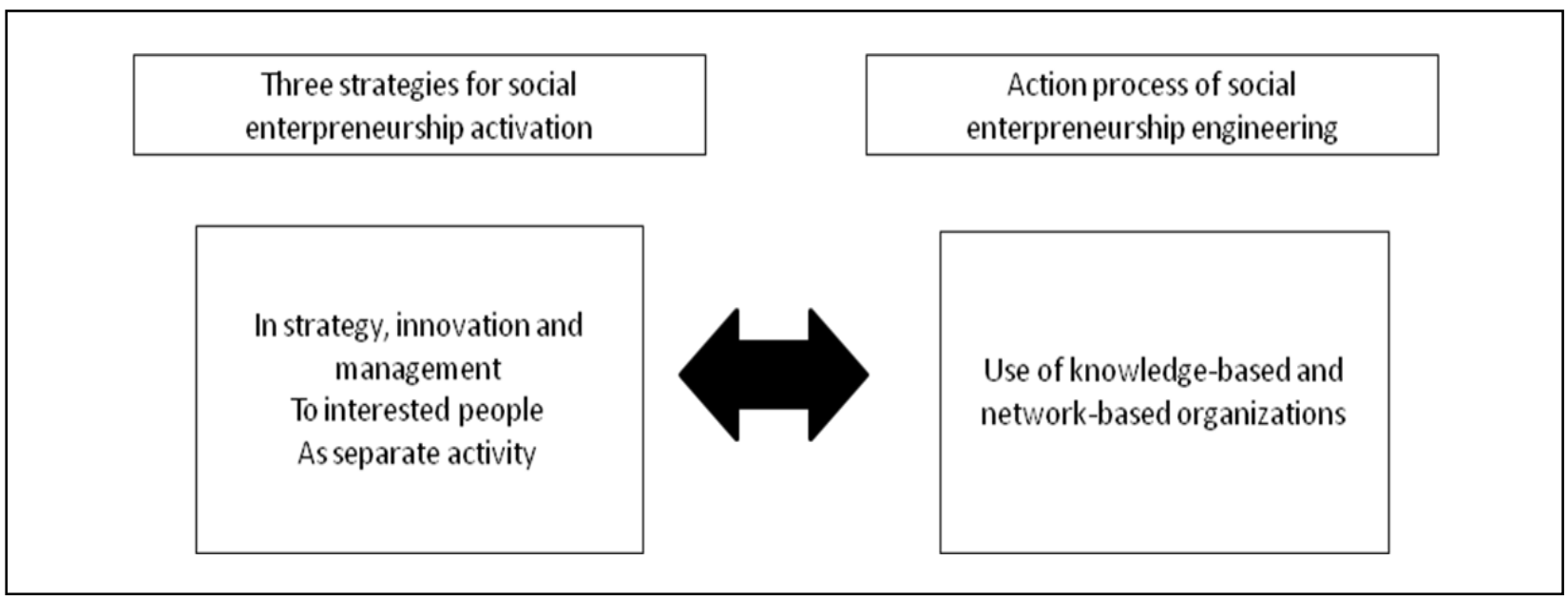

Figure 9. Connections among the strategies and action process for social enterpreneurship engineering.

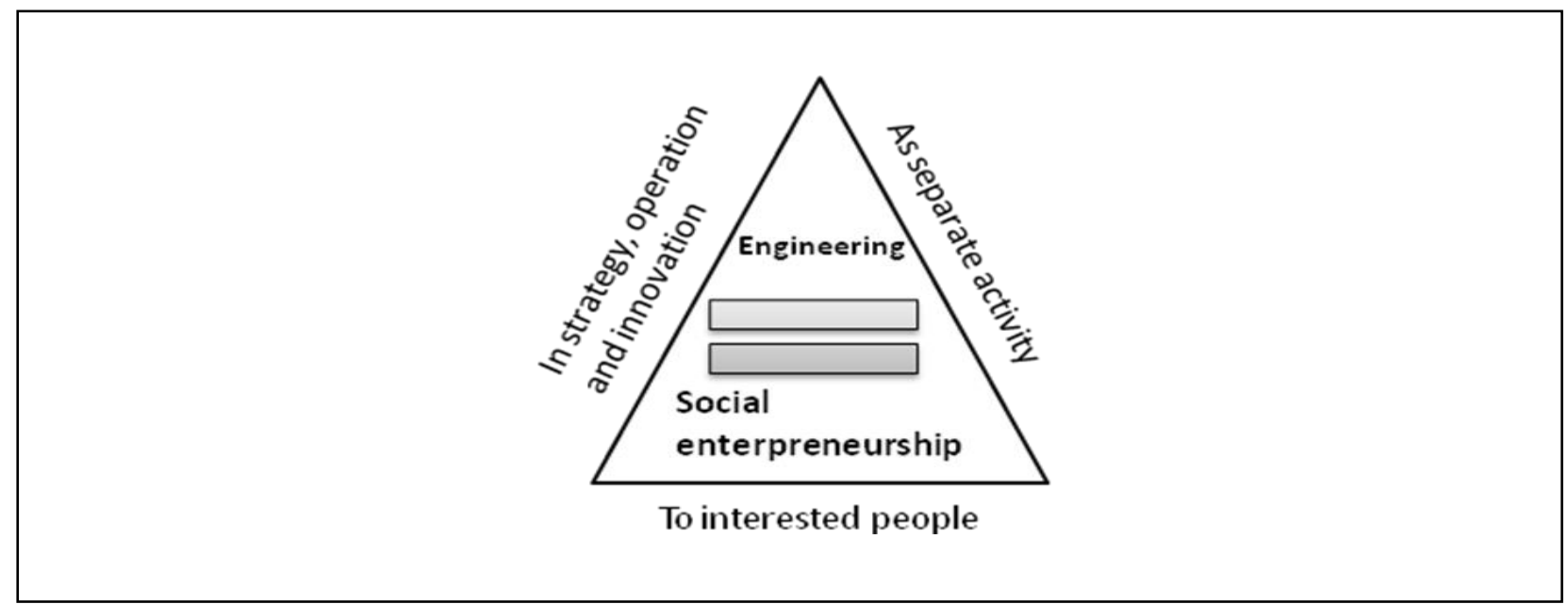

Figure 10. Three strategies for MF social enterpreneurship activation. (derived from: Elia et al. 2011)

The research paper highlights the importance of the creation of new methods in the social enterpreneurhsip engineering process in the MF sector. Some basic activities which enhance social enterpreneurship in the micro-financing sector are the introduction of social enterpreneurship as a part of all MF activities of operation, strategy, and R\&D management in general, the introduction of social enterpreneurship as a separate activity, and the provision of social entrepreneurship capacities to interested people and organizations (Figure 10). The activation process of social entrepreneurship engineering in the micro-financing sector described in the paper provides a general combination of the three strategies, and contributing to the social entrepreneurship theories and management practices; as stated by Chell, Nicolopoulou, and Karatas-Ozkan (2010), all the authors of research on social enterprise and social entrepreneurship emphasize the need to create a theoretical basis for research and to clearly present the issues in methodologies of social management practices. The contribution of this article can be found then at theoretical and practitioner levels.

\section{Implications for Theory}

The study contributes to the development of literature on organizational structure development and change and more precisely inter-organizational collaboration. The research further demonstrates the importance and 
impact of networking on the competencies, operational development, and economic performance. Besides, the research results show that inter-organizational networking can have simultaneously various objectives and strategic processes.

The research also advances theory on the micro-financing sector stating it is a dynamic environment in continuous change and development for it is in possess of capacities and competencies for innovation and knowledge creation; this contributes to innovation management discipline as well. Also, the study, based on the results, states the micro-financing sector has strategic managerial methodologies leading to its continuous success; this contributes to the entire management science disciplines.

\section{Implications for Management}

The paper provides a list of guidelines based on the results of the research. The guidelines are the mechanisms and dynamisms leading to the continuous success of the network, and they can be considered as a standard methodology for the management of networks. The guidelines are as follows:

First, the direct ties of the founders of the network are the first pillar for the success of the strategic collaboration leading to homogeneity among the members of the network. The founders must have a multi-disciplinarity background and expertise in the sector for strategic decision making.

Second, the founders and top-management of the network have capacities to delegate to the right person some operations in the network; this choice is based on the background and expertise of the person in charge of the operations and leads to a heterogeneity in active participation.

Third, the level of engagement of the members, also based on the expertise of the members, allows a clear and sustainable strategic positioning and decision making - within the network.

Fourth, the indirect ties among the members represented by the lack of consultancy are also the strategic pillars leading to the involvement of top-and-middle management and external actors, and the use of delegation.

Fifth, to allow inception and development of the network, the financial and IT-support is necessary to accelerate organizational structure development and information and communication sharing.

\section{References}

Aderibigbe, J. O. (2001). The role of the financial sector in poverty reduction. CBN Economic and Financial Review, 39(4).

Afrane, S. (2002). Impact assessment of microfinance interventions in Ghana and South Africa: A synthesis of major impacts and lessons. Journal of Microfinance, 4(1), 37-58.

Ahuja, G. (2000). Collaboration networks, structural holes, and innovation: A longitudinal study. Administrative Science Quarterly, $5(3), 425-455$.

Alade, J. A., Sharma, D. K., \& Sharma, H. P. (2003). The role of microenterprise finance in economic development. Journal of Academy of Business and Economics, 1(1).

Antohi, M. (2009). Microfinance, capital for innovation. In D. MacCallum, F. Moulaert, J. Hillier, and S. V. Haddock (Eds.) Social Innovation and Territorial Development, 3, 39-62. Farnham, England and Burlington, USA: Ashgate Publishing Limited.

Armendáriz, B., \& Morduch, J. (2005). The economics of microfinance. The MIT Press: Cambridge, Massachusetts.

Ayanwale, A. B., \& Alimi, T. (2004). Microfinancing as a poverty alleviation measure: A gender analysis. Journal of Social Sciences, 9(2), 111-117.

Barley, S. R. (1986). Technology as an occasion for structuring: Evidence from observations of ct scanners and the social order of radiology departments. Administrative Science Quarterly, 31(1), 78-108.

Baum, J., Calabrese, T., \& Silverman, B. S. (2000). Don't go it alone: Alliance networks and start-ups performance in Canadian Biotechnology. Strategic Management Journal, 21, 276-294. 
Benjelloun, A. M. (2006). Impact du micro-crédit sur l'activité économique: cas de l'ASMSSF/MC". Mémoire Online: Economie et Finance. License Fondamentale. University Sidi Mohammed Ben Abdallah, License Fondamentale http://www.memoireonline.com/12/06/310/m_impact-micro-credit-activite-economique-amssfmc1.html

Bin Mislan, W., Hadisumarto, C., \& Ismail, A. G. B. (2010). Improving the effectiveness of Islamic micro-financing: Learning from BMT experience. Humanomics: The International Journal of Systems and Ethics, 26(1), 65-75.

Brion, S., Mothe, C., \& Sabatier, M. (2012). Managing competences to enhance the effect of organizational context on innovation. In J. Tidd (Ed.), From Knowledge Management to Strategic Competences, 10, 225-251.

Bruton, G. D., Khavul, S., \& Chavez, H. (2011). Micro lending in emerging economies: Building a new line of inquiry from the ground up. Journal of International Business Studies, 42, 718-739.

Chell, E. (2007). Social enterprise and entrepreneurship: Towards a convergent theory of the entrepreneurial process. International Small Business Journal, 25(1), 5-26.

Chell, E., Nicolopoulou, K., \& Karatas-Ozkan, M. (2010). Social entrepreneurship and enterprise: International and innovation perspectives. Entrepreneurhsip and Regional Development: An International Journal, 22(6), 485-493.

Chen, B., \& Krauskopf, J. (2011). Integrated or Disconnected? Examining formal and informal networks in a merged nonprofit organization. Proceedings of the 2011 Annual Meeting of the Academy of Management.

Duvendack, M., Palmer-Jones, R., Copestake, J. G., Hooper, L., Loke, Y., \& Rao, N. (2011). What is the evidence of the impact of microfinance on the well-being of poor people? DFID Systematic Review. Research Report. London: EPPI-Centre, Social Science Research Unit, Institute of Education, University of London.

Dyer, J. H., \& Singh, H. (1998). The relational view: Cooperative strategy and sources of inter-organizational competitive advantage. Academy of Management Review, 23(4), 660-679.

Elia, G., Margherita, A., Secundo, G., \& Moustaghfir, K. (2011). An activation process for entrepreneurial engineering education: The model and application. Journal of Enterprising Culture, 19(2), 147-168.

Franciscus, J., Koppenjan, M., \& Klijn, E. H. (2004). Summing up: Dealing with uncertainties in networks. Managing Uncertainties in Networks: A Network Approach to Problem Solving, 6, 113-130, Routledge.

Galak, J., Small, D. A., \& Stephen, A. T. (2011). Micro-finance decision making: A field study of prosocial lending. Journal of Marketing Research, 48, 130-137.

Gulati, R. (1998). Alliances and networks. Strategic Management Journal, 19, 293-317.

Hartungi, R. (2007). Understanding the success factors of micro-finance institution in a developing country. International Journal of Social Economics, 34(6), 388-401.

Khandelwal, A. K. (2007). Microfinance development strategy for India. Economic and Political Weekly, 42(13), $1127-1135$.

Lebossé, J., \& Wallace, J. (1998). Micro-financing and local development. Proceedings of Local Strategies for Employment and the Social Economy, 131-139, Montréal.

Lipnack, J., \& Stamps, J. (1997). Virtual Teams. New York: John Wiley \& Sons.

Morton, M. (1997). SD helps revitalize credit unions in Africa. Office of Sustainable Developments-A News Letter. Bureau for Africa, USAID, Fall/Winter, 1997.

Murisa, T., \& Chikweche, T. (2012). Enterpreneurship and micro-finance in extreme poverty circumstances-Challenges and prospects: The case of Zimbabwe. Journal of Development Entrepreneurship, 18(1).

Nader, Y. F. (2008). Micro-credit and the socio-economic wellbeing of women and their families in Cairo. The Journal of Socio-Economics, 37(2), 644-656.

Nonaka, I., \& Takeuchi, H. (1995). The knowledge creating company: How Japanese companies create the dynamics of innovation. New York: Oxford University Press.

Orlikowski, W. J., \& Robey, D. (1991). Information technology and the structuring of organizations. Information Systems Research, 2(2), 143-169.

Peredoa, A. M., \& McLean, M. (2006). Social entrepreneurship: A critical review of the concept. Journal of World Business, 41(1), 56-65. doi:10.1016/j.jwb.2005.10.007

Roubos, K. (2008). The rise of cross-sector partnerships in microfinance: Environmental causes and future potential. Stanford Journal of Microfinance, 1.

Sapovadia, V. K. (2006). Micro-finance: The pillars of a tool to socio-economic development. Development Gateway, 6, 34-37.

Shan, W., Walker, G., \& Kogut, B. (1994). Inter-firm cooperation and start-up innovation in the biotechnology industry. Strategic Management Journal, 15(55), 387-394. 
Short, J. C., Moss, T. W., \& Lumpkin, G. T. (2009). Research in social entrepreneurship: Past contributions and future opportunities. Strategic Entrepreneurship Journal, 3(2), 161-194.

Symon, G. (2000). Information and communication technologies and the network organization: A critical analysis. Journal of Occupational and Organizational Psychology, 73(4), 389-414.

Taifi, N. (2004). Micro-financing institutions: An empirical study of the situation in the country Morocco and an economic model of the resource allocation of the MC borrower. Master of Science Thesis, Dalarna University, Sweden.

Taifi, N., \& Gharbi, K. (2013). IT integration in strategic management: The case of a micro-financing network. In T. Torres-Coronas and M-A. Vidal-Blasco (Eds.), Sociel e-Enterprise: Value creation Through ICT, 263-279.

Tidd, J. (2012). From knowledge management to strategic competences: Assessing technological, market, and organizational innovation. Series on Technology Management, 19, Worldscinet Publising.

Tiwana, A., \& McLean, E. R. (2005). Expertise integration and creativity in information systems development. Journal of Management Information Systems, 22(1), 13-43.

Yoshino, M. Y., \& Rangan, U. S. (1995). Strategic alliances: An enterpreneurial approach to globalization. Boston: Harvard Business School Press.

Zapalska, A. M., Brozik, D., \& Rudd, D. (2007). The success of micro-financing. Problems and Perspectives in Management, 5(4), 84-90.

Zhang, W., \& Gutierrez, O. (2007). Information technology acceptance in the social services sector context: An exploration. Social Work, 52(3), 221-231. 